\title{
USE OF PV PANELS FOR WATER HEATING IN ULBROKA RESEARCH CENTRE
}

\author{
Ilze Pelece, Imants Ziemelis, Henriks Putans, Liene Kancevica \\ Latvia University of Life Sciences and Technologies, Latvia \\ ilze.pelece@1lu.lv,imants.ziemelis@1lu.lv, henriksooo@inbox.lv, liene.kancevica@1lu.lv
}

\begin{abstract}
Solar energy has been widely used not only in southern countries, but also in Latvia. In Latvia solar energy has been used mainly for heating of water and/or air in summer. In the Ulbroka Research Centre starting with summer of 2008 the vacuum tube solar collector Vitosol 200 SD2 is used for water heating in summer, when the central heating system does not work. Area of this collector is $3 \mathrm{~m}^{2}$, and it works with 3001 hot water reservoir Vitocell B-100 CVB. Such collector satisfied the demand for hot water till 2013, when severe hail damaged the vacuum tubes of the collector. 9 tubes from 30 were broken. Now we propose photovoltaic (PV) panels for water heating. PV panels have some advantages in comparison with solar collectors: there is no need of the complicated system of heat exchanging and transporting of the heat from the roof of the house, where the solar collector is situated, to the rooms, where the hot water is used; there cooling is not going on, when the sun is covered by clouds; the heating power does not depend on the temperature in the hot water reservoir; it is more simple to ensure tracking to the sun for PV panels than for the solar collector. Measurements of water heating capacity of both stationary and sun tracking PV panels have been done to find out the necessary area of PV panels to satisfy the demand for hot water in the Ulbroka Research Centre. It was obtained that two PV panels Solet 60.6-WF-250, mounted on the tracker ensuring all day perpendicular striking of direct solar beams on the panel's surface, produce in average $4.66 \mathrm{kWh}$ daily in summer. Such amount of energy is sufficient to warm 150 1 of water to 26 Celsius degrees.
\end{abstract}

Keywords: solar, energy, batteries, photovoltaics, heating.

\section{Introduction}

Along with depletion of fossil fuel and bad influence of its burning on global climate, more and more attention is devoted to the use of renewable energy resources around the world. One of most popular renewable energy sources not only in southern countries, but also in northern ones is solar energy. In northern countries, such as Latvia, located at $57^{\circ}$ north latitude, there is lower solar irradiance, but longer days in summer than in the southern ones. The most popular device for transforming of solar energy in other kinds of energy is the photovoltaic (PV) panel [1]. The PV panel can be mounted on the solar tracker simpler than solar collectors. Solar tracker can enhance energy gain from the PV panel up to 1.5 times [2].

In the Ulbroka Research Centre already from 2008 solar energy is used for heating water for the needs of employees in summer, when the central heating system does not work. Till now it has been done by the vacuum tube solar collector Vitosol 200 SD2. Area of this collector is $3 \mathrm{~m}^{2}$, and it works with 3001 hot water reservoir Vitocell B-100 CVB. The demand for hot water was satisfied by such collector till 2013, when heavy hail broke 9 from 30 collector's tubes.

Now we are searching for a new heater of water for the use in the Ulbroka Research Centre. We have got for the research needs four photovoltaic (PV) panels Solet 60.6-WF-250, and a solar tracker for two of these panels. The other two are mounted stationary.

Traditionally solar energy for heating of water is used in solar collectors, but photovoltaics are used for producing of electricity. Solar collectors have higher efficiency, if only the collector itself is taken into account, but really all system and heat exchangers reduce its efficiency very much. On the other hand, cost efficiency of photovoltaic is strongly decreased by stabilizers and other devices ensuring high quality of the obtained electricity. Efficiency of photovoltaic is also highly dependent on load resistance $[3,4]$. For heating of water load resistance can be used optimal for the photovoltaic and without any converters and stabilizers.

The aim of this article is to find out, if two PV panels Solet 60.6-WF-250 mounted on the solar tracker can satisfy the demands for hot water. An additional question is, if the 3001 hot water reservoir used with the vacuum tube solar collector is usable also with these solar panels.

\section{Materials and methods}

Two PV panels Solet 60.6-WF-250 mounted on the solar tracker (Fig. 1) are used in this study. The main parameters of these panels given by the producers are: nominal power $255 \mathrm{~W}$ for each, 
efficiency $15 \%$, voltage at maximal power $30.9 \mathrm{~V}$, current at maximal power $8.06 \mathrm{~A}$, thermal coefficient of power $-0.47 \% \cdot \mathrm{K}^{-1}$, size $1640 \times 992 \times 45 \mathrm{~mm}$.

For measuring of energy received by the panels the Kipp\&Zonen ISO 1-sth class pyranometer CMP 6 was used. Global solar energy was registered automatically after every $5 \mathrm{~min}$. Then the energy received by tracking sun solar panels can be obtained from formula (1).

$$
E=\left(\frac{I-D}{\sin (h)}+D\right) \Delta t S,
$$

where $E$ - received energy, J;

$I$ - irradiance, $\mathrm{Wm}^{-2}$

$D$ - diffuse radiation, $\mathrm{Wm}^{-2}$;

$h$ - height of the sun, degrees;

$\Delta t$ - time interval between measurements, $\mathrm{s}$;

$S-$ area of the panel, $\mathrm{m}^{2}$.

Height of the sun can be obtained using the formulae explained in [5].

a)

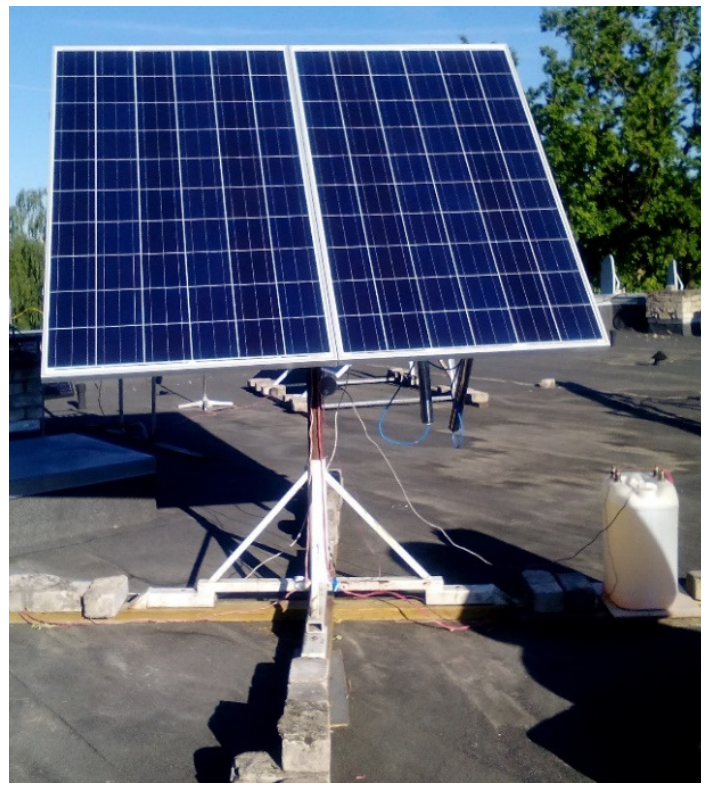

b)

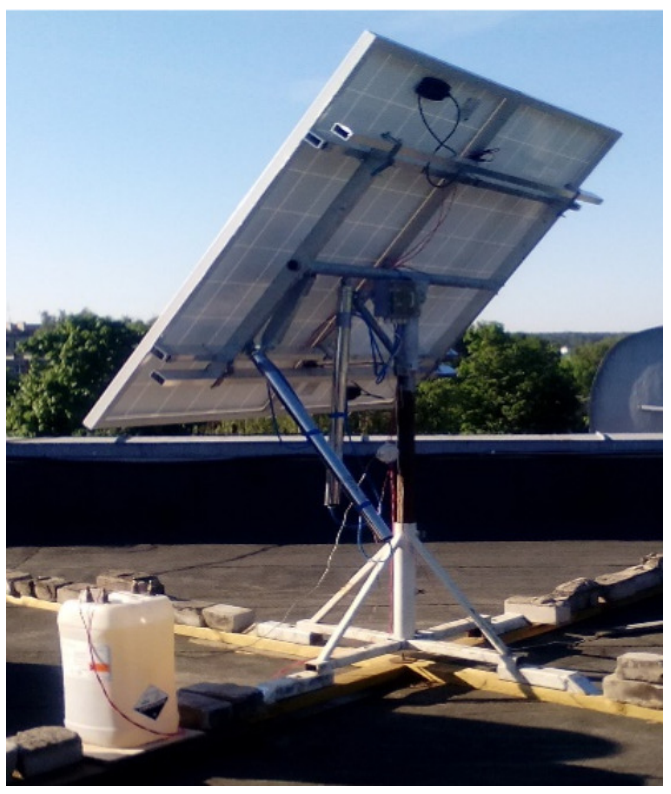

Fig. 1. PV panels (a) with solar tracker (b)

If the energy received by the panel is known, the amount of water heated by given temperature difference, or temperature difference of the given amount of water can be calculated using formula (2).

$$
\frac{E \eta}{100}=c m \Delta T,
$$

where $E$ - energy received by panel, J;

$\eta$ - efficiency, \%;

$c$ - specific heat of water, $\mathrm{J} \cdot \mathrm{kg}^{-1} \cdot \mathrm{K}^{-1}$;

$m$ - mass, $\mathrm{kg}$;

$\Delta T$ - temperature difference, $\mathrm{K}$.

As explained in [5], efficiency can be illustrated by plot of daily energy gain from the solar panel via daily sum of solar energy received by the panel.

\section{Results and discussion}

Figure 2 shows the temperature of water heated with the vacuum tube collector Vitosol 200 SD2.

It can be seen that the stationary collector Vitosol works only approximately 6 hours daily. On the first day water was heated from $20^{\circ} \mathrm{C}$ to $50{ }^{\circ} \mathrm{C}$, subsequently heat accumulates and on the fourth day 
the temperature reached $60{ }^{\circ} \mathrm{C}$. Consumption of hot water can be noticed at the midday of two days from four, but it does not affect the temperature in the reservoir significantly.

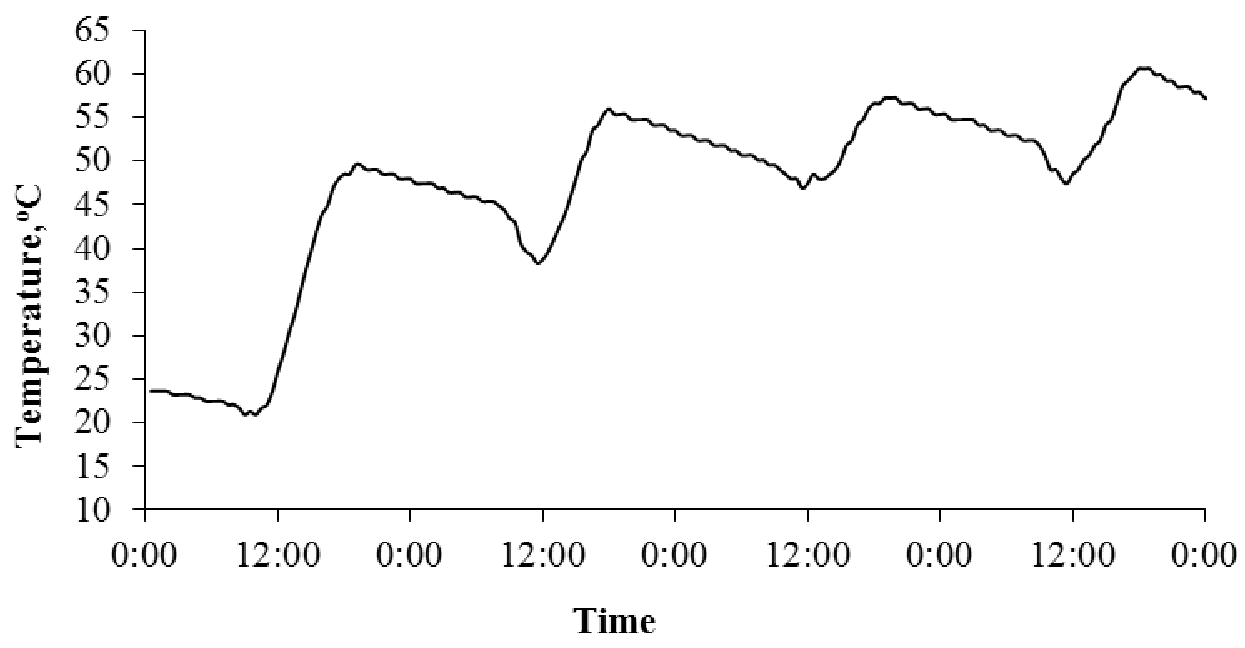

Fig. 2. Temperature of heated water, April 16-19, 2009

Daily sums of energy produced by solar batteries via those the batteries receive from the sun are plotted (Fig. 3).

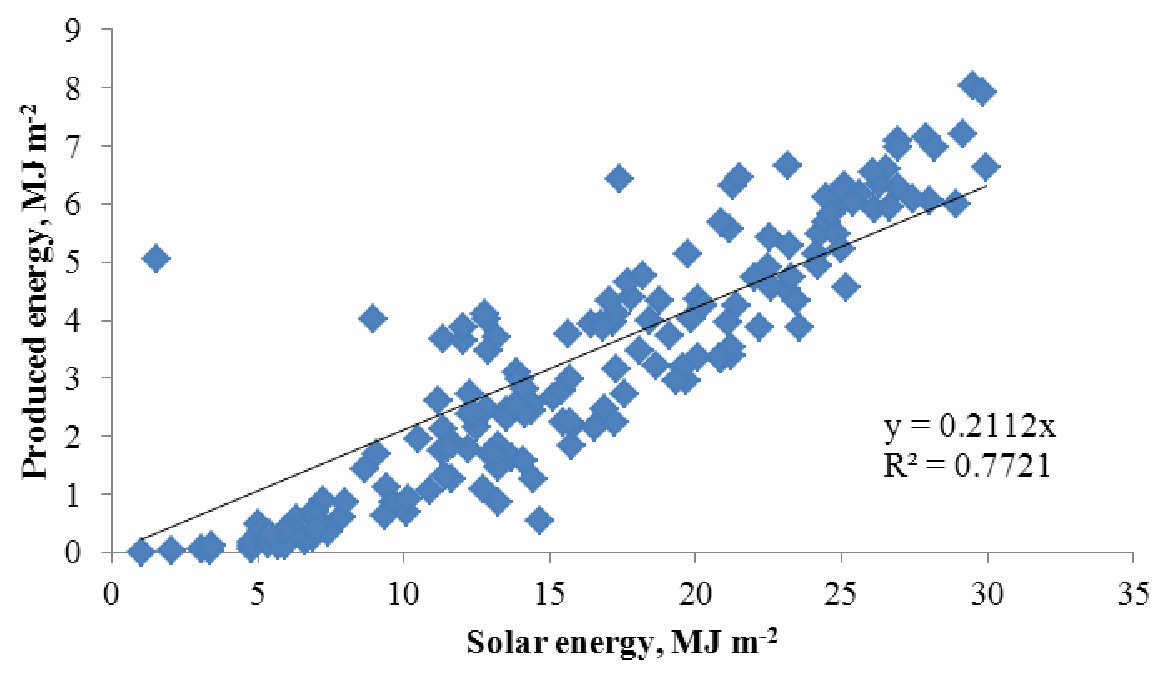
Fig. 3. Dependence of daily energy sums produced by square meter of solar batteries on those
batteries receive from the sun

As it was expected, the dependence is approximately linear. If intercept is set to zero, the slope characterizes the efficiency of the batteries. We obtained in such way the efficiency 0.21 , while the producers give 0.15 . It means that we can rely on the producer's specified efficiency; it can be higher at some conditions, but not lower.

Calculated monthly energy sums possible to receive from batteries are shown in Figure 4. They have been obtained from measured global solar energy, using formula (1). Results for three years (2014, 2015 and 2017) are shown.

We obtained that in May, June and July the monthly energy amount exceeds $500 \mathrm{MJ}$ (140 kWh) in each of these years, what means average daily energy sum $16.6 \mathrm{MJ}$ or $4.66 \mathrm{kWh}$. Such energy amount is sufficient for heating of 150 litres (heating capacity of the available boiler) of water from 20 to $46{ }^{\circ} \mathrm{C}$ (Formula (2)) every day, what is more than enough for employees in the Ulbroka Research Center. Real use of hot water is much smaller and heat accumulates. In March, April, August and September the monthly energy amount exceeds $400 \mathrm{MJ}$, what gives daily mean temperature increase 
by 21 Celsius degrees. From October till February the monthly energy amount exceeds $100 \mathrm{MJ}$, what allows to heat given amount of water by $5.6^{\circ} \mathrm{C}$ daily, what can be insufficient, although the demand for hot water in winter is less than in summer.

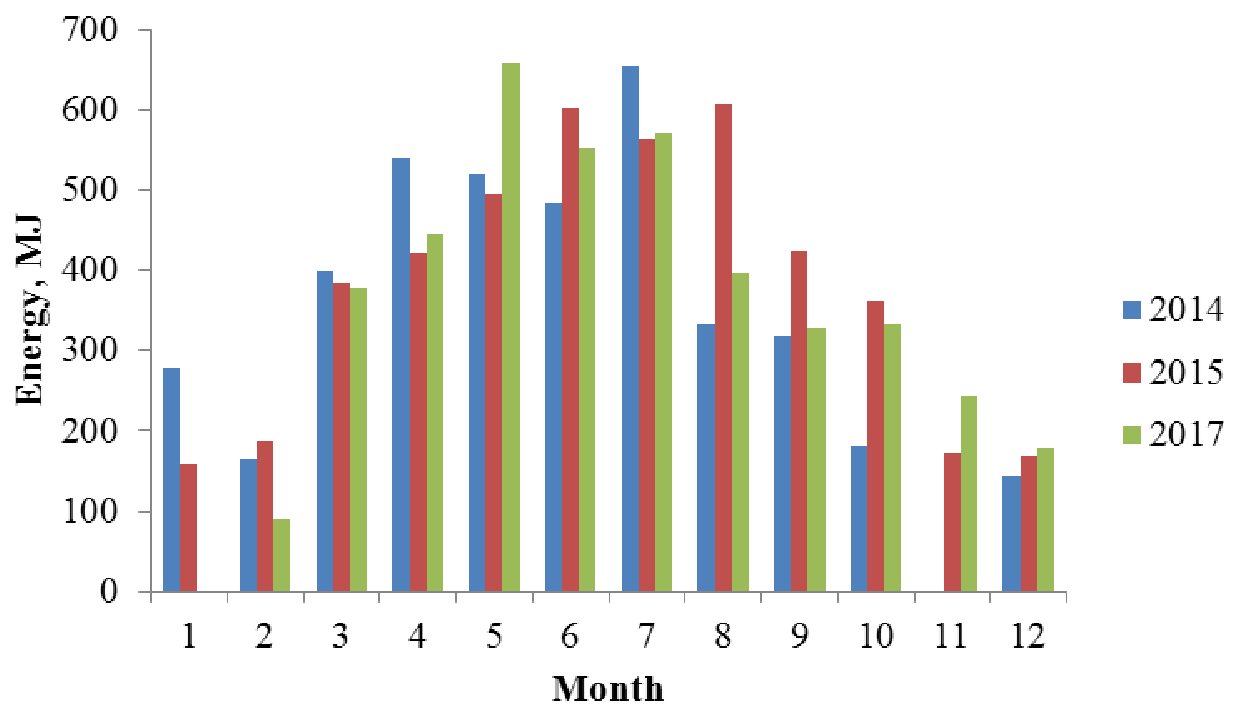

Fig. 4. Monthly energy sums possible to produce with batteries (area $3.25 \mathbf{~ m}^{2}$ )

\section{Conclusions}

1. Photovoltaic panels Solet 60.6-WF-250 can be used for water heating for needs of the employees in the Ulbroka Research Centre.

2. Two panels, mounted on the tracking device, give daily mean temperature increase of 1501 of water by more than 20 Celsius degrees from March till September.

\section{References}

[1] Gonçalves P., Sampaio V., Orestes M., González A. Photovoltaic solar energy: Conceptual framework. Review article. Renewable and Sustainable Energy Reviews, Volume 74, July 2017, pp. 590-601.

[2] Abdelghani-Idrissi M.A., Khalfallaoui S., Seguin D., Vernières-Hassimi L., Leveneur L.V.S. Solar tracker for enhancement of the thermal efficiency of solar water heating system. Renewable Energy, Volume 119, April 2018, pp. 79-94.

[3] Lin J., Liao T., Lin B. Performance analysis and load matching of a photovoltaic-thermoelectric hybrid system. Energy Conversion and Management, Volume 105, 15 November 2015, pp. 891-899

[4] Li G., Zhou K., SongZ., Zhao X., Ji J. Inconsistent phenomenon of thermoelectric load resistance for photovoltaic-thermoelectric module. Energy Conversion and Management, Volume 161, 1 April 2018, pp. 155-161.

[5] Pelece I., Shipkovs P. Theoretical and experimental investigations of cylindrical air-heating solar collector. Latvian Journal of Physics and Technical Sciences, Volume 53, Issue 3, 1 June 2016, pp. 11-21. 